Journal of Loss Prevention in the Process Industries Volume 19, Issue 6 , November 2006, Pages 719-723

doi:10.1016/j.jlp.2006.05.006

Copyright (c) 2006 Elsevier Ltd All rights reserved.

\title{
Safety distances for hydrogen filling stations
}

\section{A.J.C.M. Matthijsen ${ }^{\mathrm{a} *}$ and E.S. Kooi ${ }^{\mathrm{a}}$}

${ }^{\text {a}}$ RIVM Centre for External Safety, P.O. Box 1, 3720 BA Bilthoven, The Netherlands

* Corresponding author. Tel.: +31 30 2743574; fax: +31 152744442.

\begin{abstract}
In the context of spatial planning the Dutch Ministry of Housing, Spatial Planning and the Environment asked the Centre for External Safety of the National Institute for Public Health and the Environment (RIVM) to advice on safe distances pertaining to hydrogen filling stations. The RIVM made use of failure modeling and parameters for calculating the distance in detail. An imaginary hydrogen filling station for cars is used in the determination of 'external safety' or third party distances for the installations and the pipe work for three different sizes of hydrogen filling stations. For several failure scenarios 'effect' distances are calculated for car filling at 350 and 700 bar. Safe distances of filling stations from locations where people live and work appear to be similar for compressed hydrogen, gasoline/petrol and compressed natural gas. Safe distances for LPG are greater. A filling unit for hydrogen can be placed at gasoline/petrol-filling stations without increasing safety distances.
\end{abstract}

\section{Introduction}

'External risk' or third party risk refers to the risk to which people living or working in the vicinity of large amounts of hazardous substances are exposed. This exposure may be due to chemical incidents, such as fires, explosions or releases of toxic substances. These dangerous substances may be present in plants, storage or transport systems such as pipelines, trains or road trucks. Risk is defined as the probability of failure multiplied by effect. In the Netherlands, risk policy is expressed in terms of individual risk (IR) and societal risk (SR). Along with individual and societal risks, effect distances for accidents are important for fire brigades and other emergency services. Dutch legislation encompasses a set of three books (known as the 'colored books') for use in risk and consequence modeling:

- The Purple Book (CPR 18E, 1999) is used to determine risk scenarios, failure frequencies and other risk parameters.

- The Yellow Book (CPR 14E, 1997) is used for modeling the physical consequences of chemical releases such as discharge, dispersion and distance to heat radiation levels caused by fires.

- The Green Book (CPR 16E, 1992) is used for modeling the impact of toxic and flammable effects on human beings. 
Journal of Loss Prevention in the Process Industries Volume 19, Issue 6 , November 2006, Pages 719-723

The IR is displayed as a contour around an establishment or transport route. An imaginary person 'located' on a $10^{-6}$ contour for $24 \mathrm{~h}$ per day has a probability of one in a million per year of dying as a result of an accident involving hazardous substances in the establishment or on the transport route. No vulnerable objects, such as dwellings, larger offices and hospitals, are allowed within the $10^{-6}$ contour.

The SR represents the probability $(F)$ of several deaths $(N)$ at a time as a consequence of an accident. The 'acceptable' $F N$ curve for the SR is given by the relation $F \leqslant 10^{-3} \mathrm{~N}^{-2}$ per year. This means, for example, that the probability of 10 deaths must be smaller than one in a hundred thousand per year and the probability of a hundred deaths smaller than one in 10 million/year. SR depends on the population density.

Releases of hydrogen can be either instantaneous (e.g., the rupture of a compressor or buffer cylinder) or continuous (e.g., a leak in a pipe). Ignition of an instantaneous release will result in a vapor cloud fire. The consequences of continuous release will depend on the time of ignition; direct ignition results in a jet fire, while delayed ignition results in a flash fire (Lees, 1996). An explosion may occur if the released hydrogen piles up in a confined area or if there is a considerable amount of pipe work in the cloud envelope. Such conditions are not likely for a release of a few kilograms of hydrogen in open air. For reasons of conservatism, however, a probability of $40 \%$ is assigned to an explosion event (in case of a delayed ignition), and a probability of $60 \%$ to a flash fire (CPR $18 \mathrm{E}$, 1999). The effect distance is the distance from the release location to the spot where heat radiation equals $9.8 \mathrm{~kW} \mathrm{~m}^{-2}$, which corresponds to $1 \%$ lethality.

\section{The filling station}

Calculations were done on three imaginary filling stations with different capacities (see Table 1). For the production of hydrogen we assumed electrolysis at the small and medium stations and natural gas reforming for the large station (Weeda \& Smit, 2003). The three chosen capacities are adequate for the short, and medium term. About $15 \%$ of all Dutch cars could be provided with hydrogen if all existing gasoline filling stations in the Netherlands were to install a hydrogen filling unit (a small hydrogen filling unit at a small filling station, etc.). The large hydrogen filling station can serve 200 cars per day, which is comparable to a medium-sized gasoline and diesel oil filling station with sales of $2500 \mathrm{~m}^{3}$ gasoline/year.

A schematic diagram of the filling station is shown in Fig. 1.

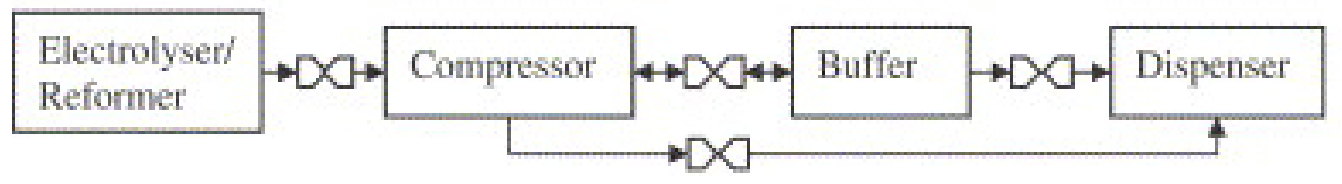

Fig. 1. Hypothetical hydrogen filling station for cars.

\subsection{Production and compression}

Hydrogen is produced at 8 bar by electrolysis or by reforming natural gas. Production takes place in a building of approximately $3 \mathrm{~m} \times 4 \mathrm{~m}$ and a height of $2.5 \mathrm{~m}$. Next to this building a compressor is placed in a structure having the same dimensions. These buildings are ventilated eight times their volume per hour and 
Journal of Loss Prevention in the Process Industries Volume 19, Issue 6 , November 2006, Pages 719-723

provided with a roof that is lifted if there is an explosion so as to discharge the explosion energy in a vertical direction. The compressor increases hydrogen pressure to 450 bar.

\subsection{Buffer}

The buffer is situated in the open air next to the compressor room. The buffer contents are equal to the daily production (see Table 1), which is quite large. Such a large buffer has the advantage that production and compressor capacity can be used for many hours a day, making this arrangement economically attractive. The buffer consists of two sections of cylinders, a low and a highpressure section, all at 300 bar when fully filled. Both sections have the same volume and contain cylinders of $50 \mathrm{I}$ each. Each section has a safety valve.

\subsection{Dispenser}

The filling hose is assumed to be $5 \mathrm{~m}$ long, with an internal diameter of $10 \mathrm{~mm}$. It is equipped with an inline breakaway coupling at each end.

\subsection{Pipe work and safety valves}

The different installations, anywhere from those for production of hydrogen to the tank of the car, are connected by pipe work with an internal diameter of $10 \mathrm{~mm}$. The cylinders in the buffer are connected by pipes of $4 \mathrm{~mm}$ in diameter. Excess flow shut-off valves are placed between the different installations, which cut off the gas flow when-in case of a rupture-the flow rate is higher than the adjusted maximum flow. These valves are installed in front of and behind the electrolyzer or reformer, behind the compressor, buffer and dispenser, on each side of the filling hose and on the car. The two valves between the buffer and the hose will normally close in the case of the filling hose rupturing. These valves will not close in case of a leak. The natural gas pipeline feeding the reformer is supposed to be laid deep enough under the ground so as not to contribute to the external risk.

\subsection{Filling}

One fill is estimated to be $2.5 \mathrm{~kg}$ of hydrogen, thus giving a car an action radius of about $250 \mathrm{~km}$. The future efficiency of a fuel cell vehicle is estimated to be $4.5 \mathrm{~g} \mathrm{H}_{2} \mathrm{~km}^{-1}$ (Markert, Nielsen, Paulsen, \& Andersen, 2005); the action radius will increase to about $1000 \mathrm{~km}$ with a future tank pressure of 700 bar. A car will tank first from the low-pressure section of the buffer and then from the highpressure section. Gas flow is driven by the pressure difference between buffer section and car tank. Finally the compressor will fill the car tank from the buffer up to 350 bar.

\section{Modeling}

In calculating, we assume the distance from production to compressor to be $5 \mathrm{~m}$, between compression and buffer, $10 \mathrm{~m}$ and between buffer and dispenser, $25 \mathrm{~m}$. The large station contains a second dispenser at $5 \mathrm{~m}$ from the first dispenser. All installations are assumed to stand in line.

The data from Table 2 are used for calculations for the medium-sized hydrogen filling station. For the small and large stations, the buffer contents and time fractions vary linearly with the number of cars per day (see Table 1). In the 
Journal of Loss Prevention in the Process Industries Volume 19, Issue 6 , November 2006, Pages 719-723

calculations for the large station we used the reformer contents of $1 \mathrm{~kg}$ hydrogen, with two dispensers instead of one.

The scenarios and data on initial frequencies of failure and the probability of direct ignition are taken from the Purple Book (CPR 18E, 1999), except for the frequency of compressor failure, which is taken from AMINAL (2004). The time fraction is the time (percentage) that cars are being filled. Assuming that it takes 3 min to fill a car, 40 cars will be filled in $2 \mathrm{~h}$, which is $8.3 \%$ of $24 \mathrm{~h}$. The mass of hydrogen for the electrolyzer unit and the compressor is estimated in accordance with suppliers. In the case of a catastrophic rupture of a cylinder, the contents of only one cylinder will be instantly released. It is not to be expected that several cylinders will rupture simultaneously. The rupture of a cylinder can cause a domino effect. As the peak overpressures are not likely to coincide, the effects of the domino event will not be considerably larger than the effects of a single event. The contents of one section will be released in the case of a catastrophic rupture of a cylinder or a pipe failure in the buffer. A leak in a filling hose or pipe work will also result in the release of a whole section. In the case of a full bore rupture the pressure drop along the pipeline is taken into account. A closing time of a fraction of a second is assumed for the valves. For this reason the scenario containing the filling-hose rupture with two functioning safety valves is ignored. This also applies to the scenario in which there is an instantaneous release or a leak in the car tank or false connection of the nozzle, since we estimated the frequency of failure to be relatively small.

The filling time for a car is $3 \mathrm{~min}$. If the hose ruptures, the safety valve will fail to close in $6 \%$ of the cases (TNO, 1983). The probability of the two valves not closing in line then is 0.0036 and the probability that one or two valves will close is 0.9964 . A leak or rupture of a pipe is modeled at half the length of the pipes. In reality rupture may occur anywhere along the pipe.

\section{Results and conclusions}

Calculations were carried out with risk software Safeti 6.42 from Det Norske Veritas (2004). This software is applicable for hazardous substances in general, but not specifically validated for hydrogen.

The results for the medium-sized filling station serve as an example for all the stations. The $10^{-6}$ IR contour calculated is shown in Fig. 2 and a transect of the risk along the line through the installations in Fig. 3. 
Journal of Loss Prevention in the Process Industries Volume 19, Issue 6 , November 2006, Pages 719-723

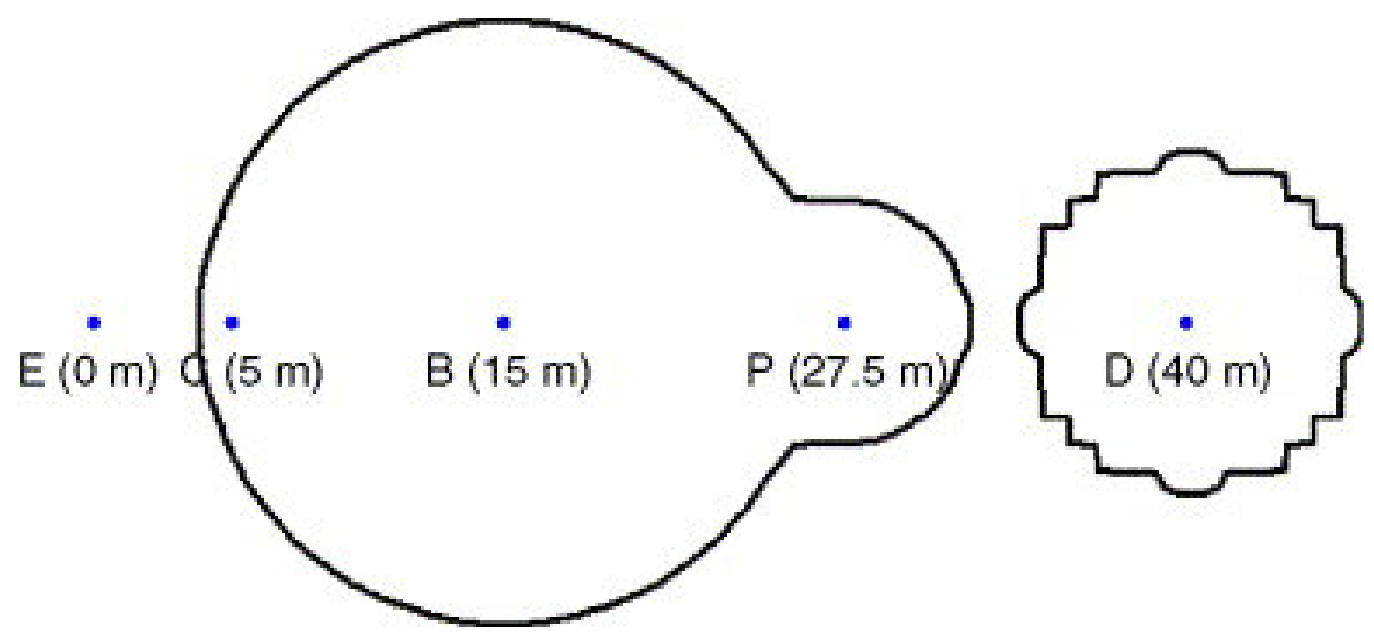

Fig. 2. IR $10^{-6}$ contour for the medium-sized hydrogen filling station.

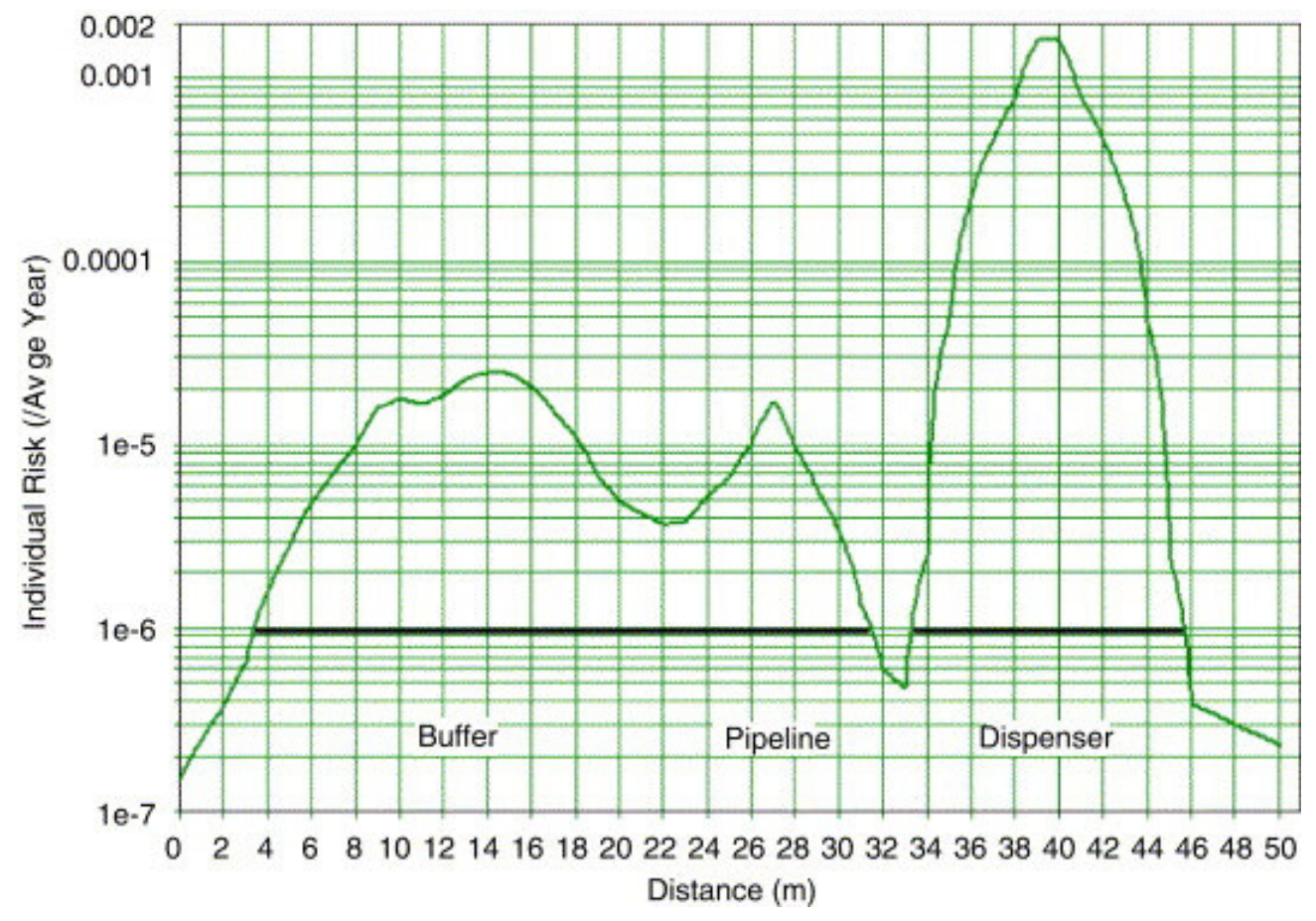

Fig. 3. Risk transect for the medium-sized hydrogen filling station.

The points in Fig. 2 represent, from left to right, the electrolyzer $(E)$, the compressor $(C)$, the buffer (B), the pipeline (P) and the dispenser (D). The two circles are the calculated $10^{-6}$ IR contours. The electrolyzer and the compressor have no significant influence on the contours. In the case of the medium-sized station the buffer has a larger contour than the dispenser. The bulge on the right side of the left contour is caused by a rupture of the pipe between the buffer and the dispenser. This rupture was modeled to take place in the middle of this $25 \mathrm{~m}$ pipeline. In practice the IR $10^{-6}$ contour is parallel to the pipeline at a distance of $4.5 \mathrm{~m}$. 
Journal of Loss Prevention in the Process Industries Volume 19, Issue 6 , November 2006, Pages 719-723

The risk transect on a line through the installations, as shown in Fig. 3, demonstrates that IR exceeds $10^{-6}$ from 3 to $32 \mathrm{~m}$ (buffer and pipeline) and from 33 to $46 \mathrm{~m}$ (dispenser). The circular risk contour round the buffer has a safety distance (radius) of $11 \mathrm{~m}$; around the dispenser this is $6.5 \mathrm{~m}$. As stated before, the pipeline has a $10^{-6}$ contour at $4.5 \mathrm{~m}$.

The risk contour around the buffer is caused by the 'catastrophic rupture of a cylinder' scenario and around the dispenser by the scenario known as 'rupture of the filling hose and both safety valves fail'.

Safety distances for the medium-sized hydrogen filling station are also determined at 700 bar.

The radii of the IR $10^{-6}$ contours for the three riskiest installations referring to the three different sized hydrogen filling stations are presented in Table 3.

The safety distances for a buffer at a filling station for 200 cars per day are about $35 \%$ greater than for 10 cars per day. The safety distance for the dispenser at the large station is twice as much as for the small station; this is caused by the two dispensers at the large station. Safety distances may be smaller for underground pipe work and buffer. An explosive gas mixture has to be prevented, for example, by effective ventilation.

The SR will not exceed the accepted $F N$ curve, not even in case of a large filling station of 200 cars per day and with a high population density around the filling station of 300 persons per hectare. There is no need to limit the allowed number of vulnerable objects like dwellings, larger offices and hospitals outside the $10^{-6}$ IR contour.

The effect distances (1\% lethal) for the different scenarios are independent of the size of a station. This is because all the parameters determining an effect, like pressure and released volume, are the same for all three stations (Table 4). The jet fire and flash fire distances at 350 bar were almost equal for all the scenarios. At 700 bar the flash fires were larger than the jet fires, sometimes even by a factor of 2 . See Table 4 for the largest effect distance per scenario.

At 350 bar, the effect distances for a medium filling station are larger than the risk based safety distances: this is because the probability of an effect is very small (see Table 2). Leaks in a buffer cylinder and ruptures in the filling hose or piping bring about the largest effect distances. Effect distances at 700 bar are approximately twice the distance at 350 bar.

Fig. 4 and Fig. 5 show the influence of Pasquill stability class (B, D, E and F) and wind velocity $\left(\mathrm{m} \mathrm{s}^{-1}\right)$ on the effect distance for the scenario 'leak in a buffer cylinder'. 
Journal of Loss Prevention in the Process Industries Volume 19, Issue 6 , November 2006, Pages 719-723

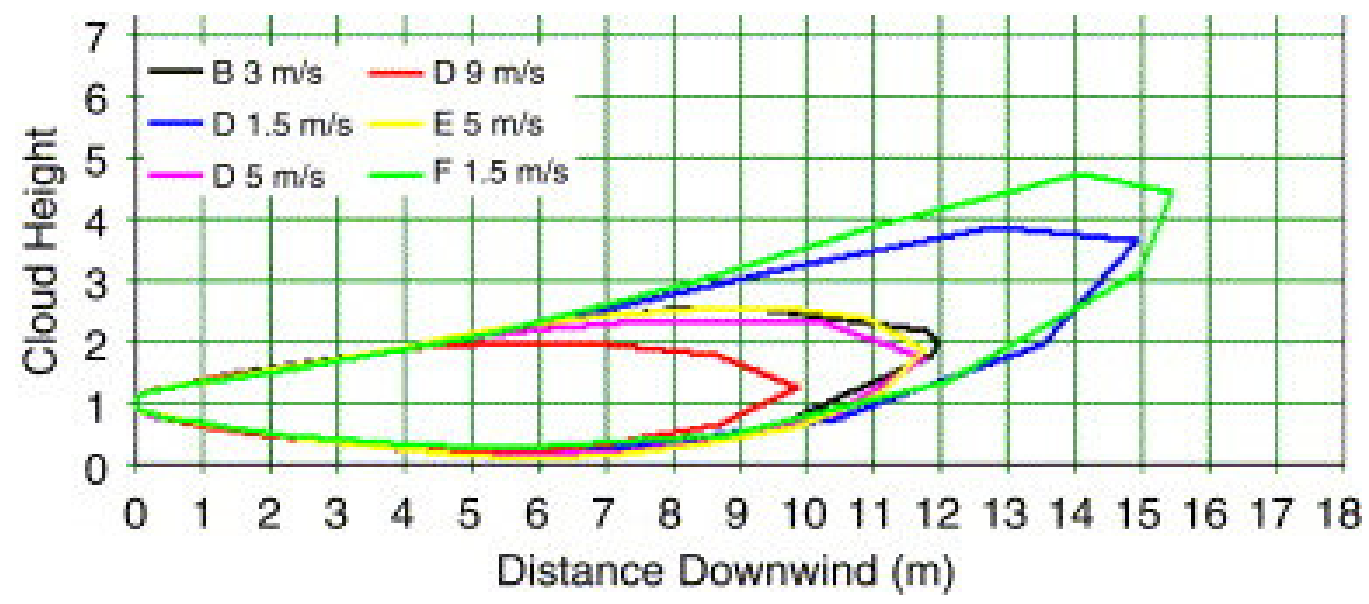

Fig. 4. Influence of stability class and wind velocity on the flame envelope (vertical cross-section).

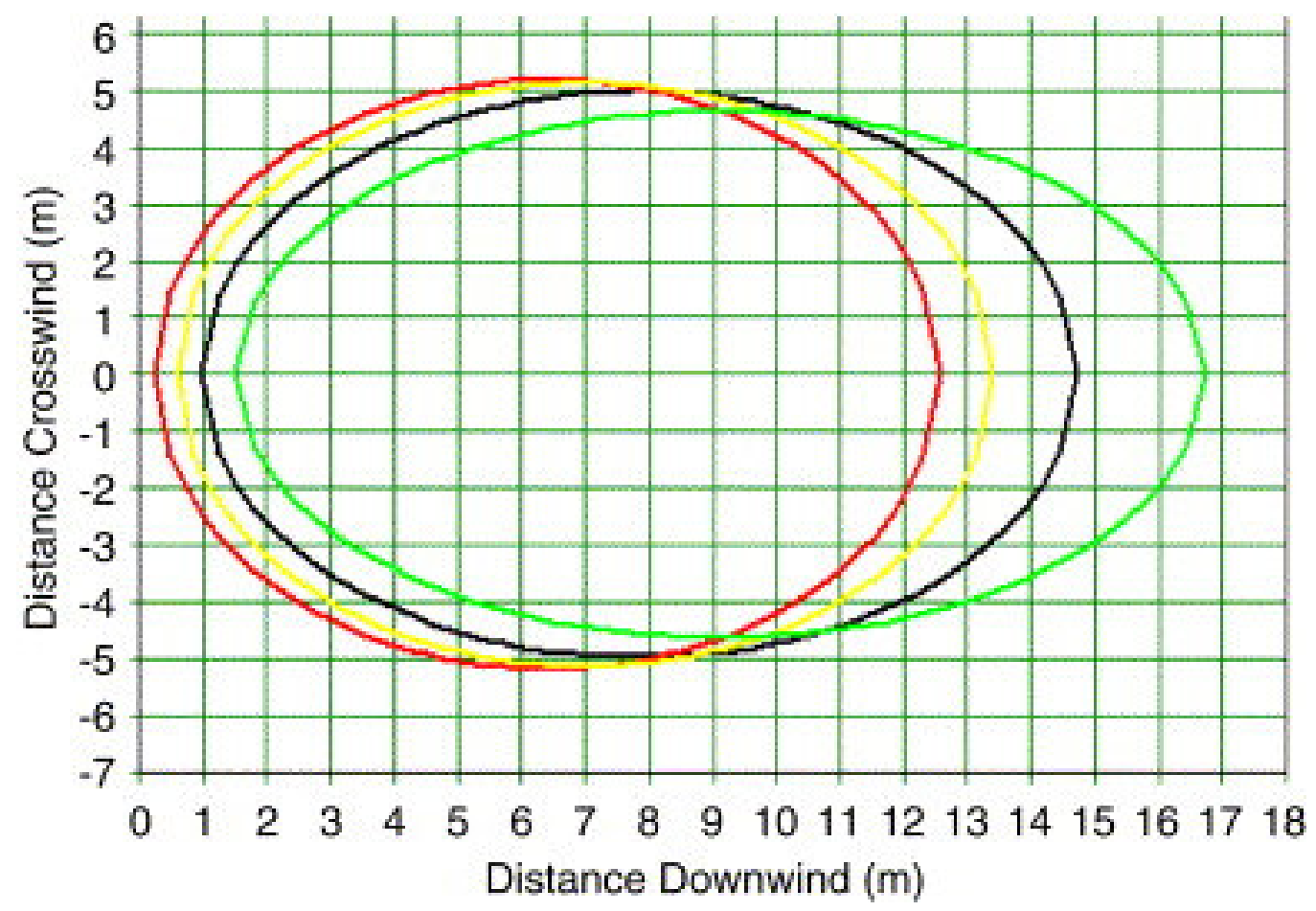

Fig. 5. Influence of wind velocity on a $1 \%$ lethality contour (horizontal crosssection).

At a wind velocity of $9 \mathrm{~m} \mathrm{~s}^{-1}$, the effect distance for a jet fire is $12.5 \mathrm{~m}$; at $1.5 \mathrm{~m} \mathrm{~s}^{-1}$ this distance is $17 \mathrm{~m}$. The stability class is not relevant for effect distances.

In comparison with other transport 'fuels', safety distances in the Netherlands for gasoline (20-25 m), CNG and hydrogen (10-15 m) are of the same order of magnitude. Safety distances for LPG are larger: $15 \mathrm{~m}$ for the dispenser, $25 \mathrm{~m}$ for the underground buffer, and, depending on annual sales, $45-110 \mathrm{~m}$ for the filling 
Journal of Loss Prevention in the Process Industries Volume 19, Issue 6 , November 2006, Pages 719-723

point on the LPG tank trailer (Government Gazette, 2004). The capacity of a hydrogen filling station does not appear to have a large influence on the safety distance. For this reason a filling station for gasoline can also be equipped with a filling unit for hydrogen without increasing the external safety distances.

\section{References}

AMINAL (2004) AMINAL (2004). Handbook probability numbers for safety reports, Version 2.0. Brussels: AMINAL (only in Dutch).

CPR 18E (Purple Book) (1999) CPR 18E (Purple Book) (1999). Guidelines for quantitative risk assessment. Committee for the Prevention of Disasters. ISSN: 0166-8935/2.10.0121/8804, Sdu Uitgevers.

CPR 14E (Yellow Book) (1997) CPR 14E (Yellow Book) (1997). Methods for the calculation of physical effects. Committee for the Prevention of Disasters. Sdu Uitgevers, ISBN9012084970.

CPR 16E (Green book) (1992) CPR 16E (Green book) (1992). Methods for the determination of possible damage. Committee for the Prevention of Disasters. ISSN: 0921-9633, Sdu Uitgevers.

Det Norske Veritas (2004) Det Norske Veritas (2004). Software for the Assessment of Flammable, Explosive and Toxic Impact (SAFETI). Version 6.420.

Government Gazette (2004) Government Gazette (2004). Law on environmental quality standards for external safety of establishments. May 27, 250 (only in Dutch).

Lees (1996) F.P. Lees, Loss prevention in the process industries. hazard identification, assessment and control (2nd ed.), Butterworth Heinemann, Oxford (1996).

Markert, Nielsen, Paulsen, \& Andersen (2005) Markert, F., Nielsen, S. K., Paulsen, J. L., \& Andersen, V. (2005). Safety aspects of land-use planning scenarios for a future infra structure with hydrogen refuelling stations. Presentation at the international conference on hydrogen safety, Pisa, Italy, 8-10 September, Risø National Laboratory, Denmark.

TNO (1983) TNO (1983). LPG integral study, report 6, sub report 1113: Probability estimation LPG (only in Dutch).

Weeda \& Smit (2003) M. Weeda and R. Smit, Infrastructural consequences for full scale hydrogen filling stations (draft), ECN (only in Dutch), Amsterdam (2003). 